\title{
Los trabajos y los meses Calcos medievales en los pasillos de la Facultad de Artes
}

\author{
Works and Months \\ Medieval Plaster Casts in the Halls of the Faculty of Arts
}

\author{
Julieta Z. Vernieri \\ julietavernieri@gmail.com \\ Marcela Andruchow \\ marcela_andruchow@yahoo.com.ar \\ Luis Disalvo \\ luisdisalvo@yahoo.com \\ Instituto de Historia del Arte \\ Argentino y Americano. Facultad \\ de Artes. Universidad Nacional \\ de La Plata. Argentina
}

Recibido: $18 / 10 / 2019$

Aceptado: 6/2/2020

\begin{abstract}
Resumen
Sin duda el significado de las obras de arte ha sido siempre un desafío para los historiadores del arte. Vislumbrar la mentalidad de los hombres que produjeron las obras del pasado, poder aproximarnos a su verdadero y original significado, requiere de un profundo conocimiento tanto del contexto histórico, económico y social como de las creencias, ideas, etcétera de la sociedad que las produjo. En este sentido, el presente trabajo tiene como objetivo ofrecer un resumen de las interpretaciones iconológicas disponibles en la bibliografía, acerca de la iconografía que tematizan tres piezas de la colección de calcos de la Facultad de Artes (FDA) de la Universidad Nacional de La Plata (UNLP) en función de ajustar las atribuciones existentes.
\end{abstract}

\section{Palabras clave}

Iconología; calcos de yeso; calendario medieval

\begin{abstract}
Undoubtedly, the meaning of the works of art has always been a challenge for art historians. Glimpsing the mentality of the men who produced the works of the past, being able to approach their true and original meaning, requires erudition, as well as a deep knowledge of the historical, economic and social context as well as of beliefs, ideas, etcetera of the society that produced them. In this sense, the present work aims to offer a summary of the iconological interpretations available in the bibliography, about the iconography that three pieces of the collection of plaster casts of the Faculty of Arts of the National University of La Plata thematize in order to precise existing attributions.
\end{abstract}

\section{Keywords}

Iconology; plaster casts; medieval calendar 
1 Proyectos de investigación del Programa de Incentivos: La colección de obras de arte de la Facultad de Bellas Artes-UNLP. Estudio histórico y artístico de los bienes, yrelevamiento de sus condiciones de conservación, registro y sistemas de guarda (código: 11/B312, período 2015-2016); La colección de obras de arte de la Facultad de Bellas Artes-UNLP. Catalogación $e$ investigación histórico-artística, técnica y material de las obras. Desarrollo de un sistema de acceso digital a la documentación y diseño de mobiliario y seguridad (código: 11/B326, período 2017-2018)
El Moisés, el Laocoonte, Sófocles, la Venus de Milo y la Venus de Arlés son quizás los calcos de yeso más reconocibles que se exhiben en los pasillos de nuestra Facultad de Artes (FDA) de la Universidad Nacional de La Plata (UNLP). Realizados en talleres de moulage europeos, una serie de copias moldeadas a partir de originales clásicos, medievales y renacentistas ingresó a nuestro país entre fines del siglo XIX y primer tercio del XX. Actualmente, cincuenta y dos calcos, algunos en yeso y otros en terracota, forman parte del patrimonio del área Museo, Exposiciones y Conservación del Patrimonio de la FDA. Como se contaba con escasa información, en 2015 se iniciaron gestiones tendientes a la puesta en valor de esta colección junto con la de otras colecciones de esculturas y de pinturas del mencionado patrimonio.

La investigación de tipo histórico artística es una de las tareas que un equipo interdisciplinario, dirigido por la investigadora y docente Marcela Andruchow, abordó dentro de los proyectos desarrollados para la puesta en valor. ${ }^{1}$ Entre los bienes patrimoniales, una serie de tres relieves en yeso devino en objeto de estudio de la tesina de grado de una de las autoras de este trabajo. Se trata de tres relieves que representan meses del calendario medieval. Durante los estudios de identificación de las piezas se evidenció que aquella conocida como la Vendimia [Figura 1, foto del medio], resultó no tener relación con la cosecha de la uva ni eran racimos lo que el campesino del relieve portaba en sus espaldas. ¿Qué era entonces lo que transportaba y qué relación tenía este calco con los otros dos elegidos para el estudio de tesis mencionado? Los tres resultaron ser copias de parte del calendario medieval tallado en piedra en el Portal de la Virgen de la Catedral de Notre-Dame de París, cada uno de ellos corresponde, respectivamente, a los meses de mayo, junio y julio [Figura 1, foto izquierda, medio, derecha, respectivamente]. La construcción de esta catedral gótica fue iniciada en 1163, mientras que los trabajos de la fachada occidental, donde se ubica el Portal de la Virgen, portal norte, comenzaron hacia 1208.

La representación plástica del ciclo calendario ya se practicaba en época antigua, pero con características iconográficas que fueron cambiando con el correr de los siglos. En el siglo IX el tipo iconográfico hoy conocido como los trabajos u ocupaciones de los meses, que se convirtió en la iconografía tradicional del calendario medieval, apareció primero en el ámbito secular y en manuscritos, para luego, ya en el siglo XII, hacer su entrada monumental en el ámbito religioso. Frecuentemente acompañado por el ciclo de los signos del Zodíaco, el ciclo calendario apareció a gran escala en los 
portales de ingreso - $\mathrm{y}$ otras veces en el interior- de las iglesias ubicadas en los caminos de peregrinación. Este tipo iconográfico, que tuvo su apogeo en las iglesias románicas y góticas de los siglos XII y XIII, se caracteriza por representar a la mayoría de los meses a través de la ejecución de faenas rurales. Algunos meses se representan por la presencia de un campesino, con vestimenta de la época, que se involucra dinámicamente en alguna actividad relacionada con la producción agrícola. Otros meses están dedicados al descanso, en correspondencia con los meses invernales, o a las celebraciones; incluso algunos están reservados a actividades de la nobleza. Este es el caso de nuestro calco correspondiente al mes de mayo, que muestra a un caballero con un pájaro en la mano izquierda, una flor (rota) en su mano derecha y abundante follaje que cuelga de este mismo brazo. Mientras en los otros dos relieves de nuestro corpus, junio y julio, un campesino porta la cosecha de heno y otro afila su herramienta de trabajo, la guadaña, respectivamente.

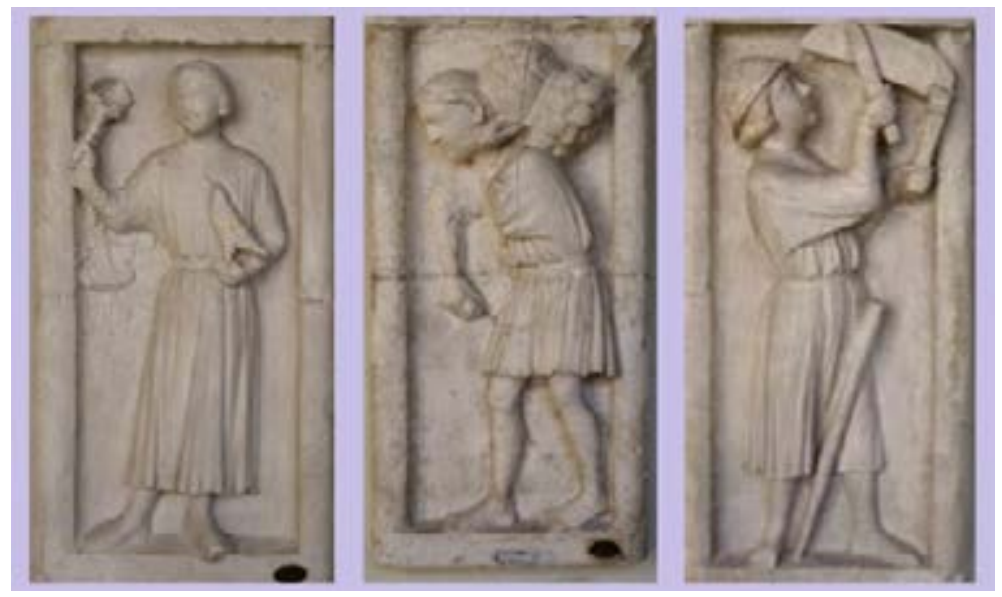

Figura 1. Calcos en yeso, de izquierda a derecha: meses de mayo, junio y julio del calendario medieval. Colección Facultad de Artes, Universidad Nacional de La Plata

¿Qué explicación podría corresponderle a la presencia de fragmentos que representan la vida rural y contemporánea, en el portal de acceso al recinto sagrado poblado de escenas del Antiguo y del Nuevo Testamento, junto a leyendas de santos y mártires?

Desde hace un tiempo, la Historia del Arte, como disciplina, se encuentra en constante revisión de sus propios fundamentos. Así se mantiene viva la llama que permite devolver el brillo a ciertos enfoques un tanto ensombrecidos por la tradición. En este contexto, 
una suerte de reivindicación crítica de la iconología en su papel de historia cultural, se posiciona con peso como una interesante e integradora alternativa metodológica. Frente a los tradicionales enfoques estilístico-formalistas, la iconología ofrece una mirada que, al alzarse más allá de la obra, busca en su contexto aquello que ayude a su comprensión y a su análisis, así como a conocer algo más de la sociedad que la produjo. La iconografía y la iconología son aplicables sin duda al arte medieval, ya que la imagen, en la acepción más amplia del término, constituyó entonces la razón última de ser del arte en cuanto vehículo de los intereses a los que sirvió (Moralejo Álvarez, 2004).

La presencia de un tema profano, como lo es el calendario, conviviendo en un edificio religioso - aunque en relación marginal y subordinado en jerarquía- con imágenes de las sagradas escrituras, de santos y de profetas, amerita un estudio profundo que bucee en las posibles interpretaciones históricas de estas imágenes, para tratar de comprender la función que cumplían en su contexto cultural.

Desde un enfoque iconológico, encontramos en la bibliografía diferentes interpretaciones que podemos agrupar en dos tendencias: una, más tradicional y frecuente, es la propuesta por Émile Mâle [1986] (2001); otra, novedosa, es la interpretación planteada por Marjorie Jean Hall Panadero (1984) y profundizada por Simona Cohen $(1990,2014)$.

Mâle es un reconocido historiador del arte francés de la primera mitad del siglo XX, especialista en el arte sacro y medieval, que se dedicó a la iconografía religiosa. Su enfoque recibió varias críticas, aunque, pese a ello, vale la pena revisar sus planteos a propósito del tema estudiado (García Mahíques, 2008). El historiador interpreta las fachadas de las catedrales como una elaboración enciclopédica:

La Edad Media concibió el arte como una pedagogía. Todo aquello cuyo conocimiento le resultaba útil al hombre: la historia del mundo desde su creación, los dogmas de la religión, los ejemplos de los santos, la jerarquía de las virtudes, la variedad de las ciencias, de las artes y de los oficios, se lo enseñaban las vidrieras de las iglesias y las estatuas de las portadas (Mâle, [1986] 2001, p. 9).

A partir de los escritos del fraile dominico Vincent de Beauvais (1190-1264), célebre enciclopedista del siglo XIII, Mâle considera 
que la presencia en el calendario del campesino que realiza actividades rurales es una forma de glorificación del trabajo.

Para Beauvais, «el hombre puede levantarse de su caída mediante la ciencia» (Mâle, [1986] 2001, p. 93), y por ciencia se debe entender el trabajo en todas sus formas, incluso las más humildes. Si bien el trabajo era considerado por la Biblia como un castigo a Adán por haber pecado, en esta época empieza a ser valorado como un camino hacia la redención.

Hay otros autores que proponen que no es necesariamente el trabajo del campesino el que se representa. De hecho, el campesino sufría de una valoración bastante negativa en la época, al considerárselo un pecador, un hombre supersticioso. Según la investigadora Nadia Lobkova (2010) no es esta actividad particular en sí la que se está representando, sino el trabajo de manera simbólica.

Una postura un tanto crítica es la de la investigadora española Inés Ruiz Montejo (1993), quien considera que la presencia del calendario en el portal de acceso al recinto sagrado, mostrando al rústico involucrado en sus tareas agrícolas, resultaría muy conveniente a la institución.

La Iglesia desea que el campesino acepte su condición como parte de un orden providencial, y encauce sus penalidades y su deseo de liberación a través de la esperanza en el más allá. [...] es el mejor ejemplo de acatamiento a un sistema social opresivo que sume en la desesperanza y en la miseria a un numeroso sector de la población rural (Ruiz Montejo, 1993, p. 492).

Quizá esta aparente glorificación de las tareas rurales como camino a la salvación no sea más que una estrategia de persuasión para asegurar, de esta manera, el orden social establecido.

Otras interpretaciones iconológicas, en virtud de la presencia del noble en algunos meses, abandonan la hipótesis de glorificación de las labores rurales en favor de una nueva línea de investigación que relaciona el calendario, no con el trabajo, sino con el tiempo.

En el siglo XII, cuando se erigen los primeros portales románicos, se da lo que algunos autores, entre ellos Jacques Le Goff [1985] (1996), Ilaman el Renacimiento del siglo XII, un renacimiento de tipo intelectual en el cual se producen debates teológicos 
en muchas áreas del conocimiento. Según Panadero (1984) las reflexiones acerca del tiempo que agitan el mundo intelectual de esta época podrían explicar la presencia del calendario en el ingreso al recinto sagrado.

Laforma en que cada civilización o cada sociedad concibe el tiempo se corresponde con su concepción del mundo, con el comportamiento de los hombres que la integran, con su conciencia, su ritmo vital y su actitud hacia las cosas. En las sociedades arcaicas se tenía una visión cíclica del tiempo, basada en su concepción mitológica. En la Antigua Grecia el tiempo era concebido como un ciclo que se repetía en el constante proceso del orden al caos y viceversa. Platón diferenciaba entre eternidad y tiempo. Para el filósofo, la eternidad pertenecía al mundo inteligible, mientras que el tiempo era una imagen sensible de aquella. Para Aristóteles el antes y el después estaban objetivamente implicados en el movimiento; de ahí que la posibilidad de cuantificar esta situación permitiera definir el tiempo. Por lo tanto, distinguió entre lo que se medía, el movimiento, y su medida, el tiempo.

Con el cristianismo se instauró una concepción lineal del tiempo, tradición tomada del judaísmo, con un principio y un fin. De todas formas, la concepción circular del tiempo de la antigüedad pervivió en la mentalidad medieval. «La supervivencia más evidente y la más eficaz de todos los mitos circulares es la rueda de la Fortuna» (Le Goff, [1982] 1999, p. 143). Otro ejemplo de tiempo circular es, precisamente, el ciclo calendario.

El primer intento metódico realizado por un autor cristiano fue el de Agustín de Hipona (354-430), quien abordó la definición del tiempo y de la eternidad como un asunto teológico. Para el padre de la Iglesia la eternidad es unidad, es lo inmutable, el presente puro en el que no existe el tiempo; mientras que el tiempo es multiplicidad, cambio y movimiento, y solo existe en la mente humana. Por ende, la historia de la humanidad es la historia de la salvación del hombre en el tiempo y, como tal, es parte del Plan Divino. Así mismo, le asignó una dimensión moral al tiempo, al considerar que el elemento temporal causa confusión mental, corrompe al hombre y lo lleva a pecar. En síntesis, entre los siglos V y XII prevaleció la tendencia a concebir el tiempo en términos de la experiencia humana, al entenderlo como algo que revela la transitoriedad, el cambio, la ilusión o el engaño, y se opone a la divina perpetuidad. 
Durante el llamado Renacimiento del siglo XII se produjo la recuperación de las fuentes científicas y filosóficas griegas gracias a las traducciones del árabe al latín que se realizaron desde fines del siglo XI. Además, el clérigo Giacomo de Venecia recuperó en forma directa -al traducir del griego al latín- parte de las obras de Aristóteles (Martínez Lorca, 2015). La renovación del pensamiento filosófico y teológico, junto con una aproximación empírica y más crítica, desembocó en un intenso debate acerca de la concepción del tiempo. Al revisar y recuperar el corpus aristotélico, el tiempo comenzó a ser percibido en términos del mundo natural y, consecuentemente, se fue alejando de la concepción subjetiva que lo asociaba a la experiencia humana, así como de la noción de eternidad. De este modo, nació una disposición a entender el tiempo como una realidad abstracta por fuera de la mente del hombre. Incluso podía aspirarse a su cuantificación como medida de movimiento, lo que generó una demanda de precisión en su medición.

En resumidas cuentas, a partir de las reflexiones de los siglos XII y XIII el tiempo dejó de ser pensado en términos subjetivos, metafísicos y morales, para ser comprendido como una dimensión independiente, cuantificable, que puede ser abstraída del evento que mide y que requiere, por tanto, un cálculo preciso. Esta inclinación a la cuantificación del tiempo estaría asociada a cambios socioeconómicos. El crecimiento de la economía mercantil que se dio entre los siglos XIII y XV aceleró los avances tecnológicos en función de una más precisa medición del tiempo. El reloj mecánico hizo su primera aparición visual en la iconografía cristiana. Se trató de un manuscrito iluminado del siglo XIII de la Biblia Moralizada (Cohen, 2014).

Fueron muchos los teólogos y los pensadores que contribuyeron a este proceso de cambios en la concepción del tiempo. Hugo de San Víctor (1096-1141) diferenció entre aeterna, lo que no tiene principio ni fin; perpetua, aquellas cosas que tienen principio, pero no fin; y temporalia, aquellas que tienen principio y fin, es decir, las cosas terrenales. Mientras la eternidad corresponde al reino celestial, in ipso coelo; el tiempo corresponde al mundo supralunar, ex ipso coelo, establecido por las revoluciones estelares; y lo temporal, al mundo sublunar, sub coelo, en otras palabras, terrenal, que se pondría en marcha por el movimiento de las estrellas. Para el teólogo alemán el tiempo cósmico es una creación divina que habría surgido con la creación del mundo y, 
por lo tanto, sería perpetuo. Las constelaciones estelares, como símbolos visibles de la inefable naturaleza divina, representarían ese tiempo cósmico. Asimismo, Hugo de San Víctor relegó las connotaciones negativas de las vicisitudes del reino sublunar al concepto de temporalia o temporal, como una categoría moral. El hombre estaría sujeto a las leyes del tiempo terrestre, al cambio, a lo transitorio, a las vicisitudes, a la caducidad. Lo novedoso a inicios del siglo XII es la diferenciación que se plantea entre estos dos conceptos de tiempo: el tiempo cósmico y el tiempo terrenal (Cohen, 2014).

Para la investigadora Cohen (2014), el Zodíaco en los portales románicos, combinado con los meses, funciona como un elemento iconográfico autónomo. Cuando estos dos ciclos aparecen juntos y ambos corren en el mismo sentido en el que el sol surca el cielo del hemisferio norte (sentido horario), pueden ser interpretados como una representación de las concepciones del tiempo que en dicha época se estaban elaborando. Una posible interpretación sería que el ciclo zodiacal representaría el tiempo cósmico, mientras que el ciclo calendario, el tiempo terrenal. En cuanto al emplazamiento arquitectónico de estos ciclos, las puertas fueron frecuentemente utilizadas en alegorías de la resurrección o de la salvación. La salida del mundo temporal y el logro de la salvación eterna serían representados simbólicamente al pasar a través del portal enmarcado por el calendario (tiempo terrenal) y el Zodíaco (tiempo cósmico), e ingresar al interior de la iglesia (eternidad), porque Él salvará a los que entren (Cohen, 1990).

El portal de la Virgen de la catedral de París, ubicado en el lado norte de la fachada occidental, está dedicado a la patrona del templo. Traza, según la tradición de la Iglesia, la muerte de María, su ascenso al Paraíso y su coronación como Reina del Cielo. En el tímpano se representa a María, que descansa en su lecho de muerte rodeada por Jesús y por los doce Apóstoles. Dos ángeles colocados a la cabeza y a los pies de María levantan su sudario y la llevan al Paraíso. En la parte superior del tímpano, María, en el Paraíso, está siendo coronada por un ángel mientras Jesús la bendice y le da el cetro.

En los montantes del mismo portal se ubican los ciclos del Zodíaco y del calendario, ambos se desarrollan en el sentido horario. Una posible interpretación, si tenemos en cuenta el contexto, indicaría que mientras el calendario representa el tiempo terrenal, los signos del Zodíaco representan el tiempo cósmico, y María, en el tímpano, 
asciende a los cielos, a la eternidad. De este modo, al ingresar a la iglesia y traspasar el umbral, el fiel abandonaría ese tiempo terrenal del pecado y atravesaría el tiempo cósmico para ingresar así en la eternidad.

Como silenciosos e indiferentes testigos de lo que acontece en los pasillos de la FDA, los calcos han estado allí por años. Los estudiantes los han incorporado en su cotidiano trajín. Atractivos e interesantes para mentes curiosas, poderosos significantes pasibles de desafiantes resignificaciones, estos bienes culturales poseen un alto valor patrimonial, histórico, estético, técnico, pedagógico y de referencia historiográfica. Son múltiples los enfoques desde los que, como estudiosos del arte y de su historia, podemos abordarlos.

Este estudio profundizó en la interpretación del sentido histórico cultural de las imágenes, en particular, de estos bienes de la colección de la FDA. Asimismo, contribuyó a corregir cuestiones de atribución iconográfica (Vernieri, 2019).

\section{Referencias}

Cohen, S. (1990). The Romanesque Zodiac: its Symbolic Function on the Church Facade [El Zodiaco románico: su función simbólica en la fachada de la iglesia]. Arte Medievale, 4(1), 43-54.

Cohen, S. (2014). Transformations of Time and Temporality in Medieval and Renaissance Art [Transformaciones del tiempo y la temporalidad en el arte medieval y renacentista]. Recuperado de: https://books.google.com.ar/books?id=yqQdAwAAQBAJ\&lpg=PR $5 \&$ ots=bWl3McuuxD\&lr\&pg=PR5\#v=onepage\&q\&f=false

García Mahíques, R. (2008). Iconografía e iconología. La Historia del arte como Historia cultural. Vol. 1. Madrid, España: Encuentro.

Le Goff, J. [1985] (1996). Los intelectuales en la Edad Media. Barcelona, España: Gedisa.

Le Goff, J. [1982] (1999). La civilización del occidente medieval. Ciudad Autónoma de Buenos Aires, Argentina: Paidós. 
Lobkova, N. (2010). The cycle of the year: The genre of calendar illustrations from origins to Lucas and Maarten Van Valckenborch [El ciclo del año: el género de ilustraciones de calendario desde los orígenes hasta Lucas y Maarten Van Valckenborch] (Tesis de maestría). Recuperado de https://ib.ugent.be/fulltxt/ RUG01/001/457/590/RUG01-001457590_2011_0001_AC.pdf

Mâle, E. [1986] (2001). El arte religioso francés del siglo XIII en Francia. El Gótico. Madrid, España: Encuentro.

Martínez Lorca, A. (2015). La filosofía medieval. De al-Farabi a Ockham. Barcelona, España: EMSE EDAPP S.L.

Moralejo Álvarez, S. (2004). Formas elocuentes. Reflexiones sobre la teoría de la representación. Madrid, España: Akal.

Panadero, M. J. H. (1984). The labors of the months and the signs of the zodiac in twelfth-century french facades (Volumes I-II) [Las labores de los meses y los signos del zodiaco en las fachadas francesas del siglo XII (Volúmenes I y II)] (PH.D. Dissertation). The University of Michigan, Michigan, Estados Unidos.

Ruiz Montejo, I. (1993). El calendario de Beleña de Sorbe. Anales de la Historia del Arte, (4), 491-504. Recuperado de https://revistas. ucm.es/index.php/ANHA/article/view/ANHA9394110491A

Vernieri, J. Z. (2019). La representación del calendario medieval en tres calcos de yeso de la colección de arte de la FBA-UNLP. Investigación histórica e iconográfica (Tesis de grado). Recuperado de http://sedici.unlp.edu.ar/handle/10915/80524 